\title{
Atypical Mucin Expression Predicts Worse Overall Survival in Resectable Pancreatic Ductal Adenocarcinoma
}

Yu Liu

Fudan University Shanghai Cancer Center

Yunzhen Qian

Fudan University Shanghai Cancer Center

Yitao Gong

Fudan University Shanghai Cancer Center

Ruijie Wang

Fudan University Shanghai Cancer Center

Zhengjie Dai

Fudan University Shanghai Cancer Center

Xuan Zou

Fudan University Shanghai Cancer Center

Yesiboli Tasiheng

Fudan University Shanghai Cancer Center

Guopei Luo

Fudan University Shanghai Cancer Center

Xuan Lin

Fudan University Shanghai Cancer Center

Xu Wang

Fudan University Shanghai Cancer Center

Xianjun Yu

Fudan University Shanghai Cancer Center

Yusheng Chen

Fudan University Shanghai Cancer Center

He Cheng

Fudan University Shanghai Cancer Center

Chen Liu ( $\square$ liuchen@fudanpci.org )

Fudan University Shanghai Cancer Center 
Keywords: Pancreatic ductal adenocarcinoma, MUC1, MUC2, MUC5, prognosis prediction

Posted Date: June 3rd, 2022

DOI: https://doi.org/10.21203/rs.3.rs-1299248/v2

License: (c) (1) This work is licensed under a Creative Commons Attribution 4.0 International License. Read Full License 


\section{Abstract}

\section{Background}

Pancreatic ductal adenocarcinoma (PDAC) has a typical mucin expression pattern which is characterized as MUC1 positive, MUC2 negative and MUC5 positive. Mounting evidence has shown that mucins are involved in the development of pancreatic diseases. However, the correlation between mucin expression and prognosis of PDAC patients is controversial over the decades; thus, we aim to figure out the association of mucin expression with survival among PDAC patients who underwent radical resection.

\section{Methods}

We performed immunohistochemistry to detect the expression of MUC1, MUC2 and MUC5 in 427 resected PDAC specimens and got corresponding clinical statistics to conduct a retrospective study. Kaplan-Meier methods and Mantel-Cox tests were used to compare the survival curves, and Cox regression model was employed to make multivariate analyses and determine independent risk factors. The goat serum that we used purchase from Beijing Solarbio Science \& Technology Co, item No: SL038-100ml.

\section{Ethical statement}

We confirm that all methods were carried out in accordance with relevant guidelines and regulations in the Ethics approval and consent to participate section under Declarations in the manuscript.

\section{Results}

Log-rank tests demonstrated that MUC1 absence is significantly correlated with worse overall survival (OS) $(p=0.0079)$. MUC2 expression showed marginal significance in predicting shorter OS of PDAC patients $(p=0.055)$, while MUC5 did not show prognostic value. Besides, MUC1 absence is associated with increased proportion of stage III PDAC $(p=0.011)$. MUC1 absence and MUC2 expression are also associated with tumor perineural aggression $(p=0.011$ and $p=0.030)$. Multivariable adjusted hazard ratio (HR) for mortality of MUC1 and MUC2 is 0.492 (95\% Cl: $0.274-0.883, \mathrm{p}=0.017)$ and $1.596(95 \% \mathrm{Cl}$ : 1.061-2.401, $\mathrm{p}=0.025$ ) respectively.

\section{Conclusions}

MUC1 negative expression or MUC2 positive expression is independently associated with poor overall survival among patients with resectable PDAC.

\section{Introduction}

Pancreatic ductal adenocarcinoma (PDAC) is a notorious malignancy with poor survival. PDAC has an increasing incidence over the decades and is anticipated to be second top cancer killers in $2030^{1}$. However, there is only marginal improvement of the prognosis of PDAC; therefore, detecting prognostic 
factors and potential therapy targets has a great importance for PDAC. Notably, PDAC is characterized by aberrant glycosylation and stroma formation.

Mucins are a group of O-glycoproteins which are composed of a protein backbone and great quantities of carbohydrate side chains with abundant threonine and serine ${ }^{2}$, and could be categorized into secretory mucins and membrane-bond mucins ${ }^{3}$. Alteration of mucins are widely detected in epithelial neoplastic lesions such as PDAC, breast cancer, ovarian cancer and colon cancer ${ }^{4}$. Mucins are important markers for recognizing tumour lineage and differentiating tumour subsets ${ }^{5}$; certain mucin expression pattern indicates specific tumour type ${ }^{6}$ such as mucinous cystic neoplasms (MCN) and intraductal papillary mucinous neoplasms (IPMN), which are potential precursors of PDAC. Strikingly, mucins are not only bystanders but also culprits for PDAC tumorigenesis and development; apart from its prognostic value, there is increasing evidence indicating that mucin are involved in the inflammation and oncogenesis.

MUC1, which is also known as carbohydrate antigen $15-3$ (CA15-3), is the predominantly expressed membrane-bound mucin in normal pancreatic duct cells, and PDAC commonly have an significantly elevated level of sialynated MUC ${ }^{7}$. MUC2 is secreted to form insoluble mucous gel barrier and generally identified as a tumour suppressor ${ }^{8}$, both normal pancreatic tissue and PDAC rarely have a positive expression of MUC2. Another gel forming mucin MUC5, on the contrary, is abundantly overexpressed in PDAC tissues and potentiates oncogenic signalling pathway ${ }^{9}$. Correspondingly, these aberrantly glycosylated mucins can be recognized as tumour associated antigens, which could be employed as useful predictors for the effectiveness of adjuvant therapy ${ }^{10,11}$ and potential targets for cancer therapy ${ }^{12}$. For instance, MUC1 has epitopes for cytotoxic T lymphocytes ${ }^{13}$ and has the promise to develop cancer vaccines or chimeric antigen receptor $\mathrm{T}^{\text {cells }}{ }^{14}$.

Mucin expression pattern is altered throughout the progression and metastasis of PDAC ${ }^{9,15}$, and MUC1 positive, MUC2 negative and MUC5 positive have been considered as the typical mucin expression pattern of PDAC ${ }^{16,17}$. However, there still exists a subgroup with atypical mucin expression pattern who comprise approximately 20 to 30 percent of PDAC patients, and prior studies have inconsistent conclusions about the association between mucin expression and PDAC patients' survival. Investigating subsets of PDAC patients contributes to developing precision oncology and targeted therapy in PDAC; hence, it is of great importance to ascertain the correlation between atypical mucin expression and PDAC development.

In this study, we used immunohistochemistry (IHC) to determine the expression of MUC1, MUC2, MUC5 in resected PDAC tissues and analysed its correlation with clinicopathologic characteristics and postoperative survival of patients in Chinese population.

\section{Methods}

\section{Design and patients}


Tumour specimens were obtained from 427 Chinese patients who underwent radical surgical resection and had definite postoperative pathological diagnosis of PDAC from March 2012 to May 2017 in the Department of Pancreatic Surgery Shanghai Cancer Center, Fudan University, China. Patients were $X X X X X X X$

Patients with following features were excluded: (1) patients without follow-up data; (2) patients with multiple primary malignancies or secondary malignancies; (3) patients with pancreatic neoplasms other than PDAC; (4) patients with haematological disorders; and (5) patients died within 90 days due to surgical complications.

\section{Baseline and clinicopathological characteristic data}

Information about age, gender, tumour grade, tumour-node-metastasis (TNM) stage, tumour location, status of perineural infiltration, vascular invasion, diabetes mellitus history, carbohydrate antigen 19-9 (CA19-9) level and adjuvant therapy history were acquired from the patients' medical history from Shanghai Cancer Center. CA19-9 levels were collected according to the preoperative serum tests. Tumour grade was assessed according to the fifth edition of the WHO Classification of Tumours ${ }^{18}$ and was reviewed by expert pathologists. Tumor-node-metastasis stage was determined based on the American Joint Committee on Cancer (AJCC), 8 th edition ${ }^{19}$, and tumour size, numbers of metastatic lymph nodes and status of metastasis were recorded according to the histological pathological reports of resected specimens. OS was defined as the length of time (days) from diagnosis to death from any cause (or the last reliable follow-up). Follow-up ended in March 2021.

\section{Immunohistochemistry}

Tumour specimens acquired from operation were fixed in 10\% formalin and embedded with paraffin. Then, tissue blocks were sectioned to 4-micron thick slices and mounted to slides. After deparaffinization and rehydration, $3 \% \mathrm{H}_{2} \mathrm{O}_{2}$ was used to block endogenous peroxidase for 15 minutes. Then, antigen retrieval was accomplished by heating slices for 10 minutes within Tris-EDTA buffer $(\mathrm{pH}=9.0)$ and slides were blocked in $2.5 \%$ goat serum for one hour.

Expression of mucin were detected by using following primary monoclonal antibodies (MAbs) which were purchased from Abcam company: ab109185 (recombinant MAb to MUC1), ab134119 (recombinant Mab to MUC2) and ab3649 (recombinant MAb to MUC5). Primary antibodies were diluted against $2.5 \%$ goat serum according to instructions and were incubated with tumour tissue slides overnight at $4{ }^{\circ} \mathrm{C}$. The next day, the sections were incubated with secondary antibodies (GTVisionTM III Detection System/Mo\&Rb, GK500710, Gene Tech Company) for one hour, then 3,3-diaminobenzidine was used to coloration with counterstaining of hematoxylin. Sections were dehydrated in ethanol and xylene and re-embedded in neutral resin before observation under microscopy.

Tumors were classified into three histology grades according to their heterogeneity, differentiation level and nuclear split phases: low grade, moderate grade and high grade. The expression of mucin was 
classified as negative or positive, and positive expression was only considered when positive reaction products localized in the expected cellular component. One positive cell found was sufficient for diagnosing positive mucin expression. Some of slides were excluded from following analysis because of unsatisfactory tissue quality such as tissue tears or folds.

The results of IHC were assessed by two experienced pathologists. When the two pathologists got different results, the third pathologist participated in the discussion and came to the final conclusion or abandoned uncertain results. The pathologists evaluating the MUC staining were blinded to patients' outcomes to minimize bias.

\section{Statistical analysis}

Pearson's $\chi 2$ test and Fisher's exact test were used to analyse the correlations between mucin expression and major baseline and clinicopathological characteristics. Kaplan-Meier method was used to plot survival curves and Log-rank (Mantel-Cox) tests were used to compare the difference between groups. Cox proportional hazard models and logistic regression models were used to made multivariate analyses, and parameters with a $p$ value less than 0.10 in the univariate analyses were included in the multivariate analyses. All statistics were analysed by SPSS 26.0 software (SPSS, Inc., Chicago, IL). All p values are two-sided and differences with $p$ values less than 0.05 were considered statistically significant.

The major objective of this research is to figure out the correlation between mucin expression and OS of PDAC patients in order to find risk factors for PDAC management and potential targets for future treatment. Additional objective is finding the associations between mucin expression and clinicopathological features. This study was approved by the Ethics Board of Shanghai Cancer Center, Fudan University, and all the involved patients provided informed consent for their personal data being used for research purposes.

\section{Results}

\section{Baseline and Clinicopathological characteristics}


Table 1

Clinicopathological characteristics of PDAC patients stratified by MUC1 expression.

\begin{tabular}{|c|c|c|c|}
\hline variables & MUC1 negative & MUC1 positive & $\mathbf{P}$ \\
\hline Age, (n\%) & & & 0.303 \\
\hline$<62$ & $19(55.9 \%)$ & $183(46.7 \%)$ & \\
\hline$\geq 62$ & $15(44.1 \%)$ & $209(53.3 \%)$ & \\
\hline Sex, $(n \%)$ & & & 0.110 \\
\hline Male & $24(70.6 \%)$ & $218(56.5 \%)$ & \\
\hline Female & $10(29.4 \%)$ & $168(43.5 \%)$ & \\
\hline Tumour grade, (n\%) & & & 0.534 \\
\hline Low & $2(5.9 \%)$ & $17(4.4 \%)$ & \\
\hline Moderate & $23(67.6 \%)$ & $230(59.7 \%)$ & \\
\hline High & $9(26.5 \%)$ & 138(35.8\%) & \\
\hline Tumour stage, (n\%) & & & 0.011 \\
\hline I & $15(44.1 \%)$ & 154(39.3\%) & \\
\hline II & $10(29.4 \%)$ & 195(49.7\%) & \\
\hline III & $9(26.5 \%)$ & $43(11.0 \%)$ & \\
\hline T stage, $(\mathrm{n} \%)$ & & & 0.591 \\
\hline T1 & $8(23.5 \%)$ & $67(17.1 \%)$ & \\
\hline T2 & $19(55.9 \%)$ & $225(57.4 \%)$ & \\
\hline T3 & $7(20.6 \%)$ & $100(25.5 \%)$ & \\
\hline N stage, (n\%) & & & 0.499 \\
\hline NO & $19(55.9 \%)$ & 197(51.0\%) & \\
\hline N1 & $10(29.4 \%)$ & $149(38.6 \%)$ & \\
\hline N2 & $5(14.7 \%)$ & $40(10.4 \%)$ & \\
\hline Tumour location, (n\%) & & & 0.222 \\
\hline Head & $20(58.8 \%)$ & $210(54.4 \%)$ & \\
\hline Body & $13(38.2 \%)$ & $174(45.1 \%)$ & \\
\hline Tail & $1(2.9 \%)$ & $2(0.5 \%)$ & \\
\hline
\end{tabular}




\begin{tabular}{|c|c|c|c|}
\hline variables & MUC1 negative & MUC1 positive & $\mathbf{P}$ \\
\hline Vascular invasion, (n\%) & & & 0.681 \\
\hline No & $10(29.4 \%)$ & $101(26.2 \%)$ & \\
\hline Yes & $24(70.6 \%)$ & $285(73.8 \%)$ & \\
\hline Perineural infiltration, $(\mathrm{n} \%)$ & & & 0.011 \\
\hline No & $25(73.5 \%)$ & $342(88.6 \%)$ & \\
\hline Yes & $9(26.5 \%)$ & $44(11.4 \%)$ & \\
\hline Diabetes Mellitus, (n\%) & & & 0.226 \\
\hline No & $26(76.5 \%)$ & $326(84.5 \%)$ & \\
\hline Yes & $8(23.5 \%)$ & $60(15.5 \%)$ & \\
\hline variables & MUC2 negative & MUC2 positive & $\mathrm{P}$ \\
\hline Age, $(n \%)$ & & & 0.905 \\
\hline$<62$ & $167(47.0 \%)$ & $33(47.8 \%)$ & \\
\hline$\geq 62$ & $188(53.0 \%)$ & $36(52.2 \%)$ & \\
\hline Sex, $(n \%)$ & & & 0.760 \\
\hline Male & $201(57.4 \%)$ & $41(59.4 \%)$ & \\
\hline Female & $149(42.6 \%)$ & $28(40.6 \%)$ & \\
\hline Tumour grade, (n\%) & & & 0.171 \\
\hline Low & $13(3.7 \%)$ & $6(8.7 \%)$ & \\
\hline Moderate & $214(61.3 \%)$ & $38(55.1 \%)$ & \\
\hline High & $122(35.0 \%)$ & $25(36.2 \%)$ & \\
\hline Tumour stage, (n\%) & & & 0.699 \\
\hline I & $143(40.3 \%)$ & $26(37.7 \%)$ & \\
\hline II & $167(47.0 \%)$ & $36(52.2 \%)$ & \\
\hline III & $45(12.7 \%)$ & $7(10.1 \%)$ & \\
\hline T stage, $(\mathrm{n} \%)$ & & & 0.730 \\
\hline T1 & $64(18.0 \%)$ & $10(14.5 \%)$ & \\
\hline T2 & $204(57.5 \%)$ & $40(58.0 \%)$ & \\
\hline T3 & $87(24.5 \%)$ & $19(27.5 \%)$ & \\
\hline
\end{tabular}




\begin{tabular}{|llll|}
\hline variables & MUC1 negative & MUC1 positive & P \\
\hline N stage, (n\%) & & & 0.746 \\
\hline N0 & $182(52.0 \%)$ & $33(47.8 \%)$ & \\
\hline N1 & $130(37.1 \%)$ & $29(42.0 \%)$ & \\
\hline N2 & $38(10.9 \%)$ & $7(10.1 \%)$ & \\
\hline Tumour location, (n\%) & & & 0.407 \\
\hline Head & $191(54.6 \%)$ & $39(56.5 \%)$ & \\
\hline Body & $158(45.1 \%)$ & $29(42.0 \%)$ & \\
\hline Tail & $1(0.3 \%)$ & $1(1.4 \%)$ & \\
\hline Vascular invasion, (n\%) & & & \\
\hline No & $92(26.3 \%)$ & $19(27.5 \%)$ & \\
\hline Yes & $258(73.7 \%)$ & $50(72.5 \%)$ & \\
\hline Perineural infiltration, (n\%) & & & \\
\hline No & $312(89.1 \%)$ & $55(79.7 \%)$ & \\
\hline Yes & $38(10.9 \%)$ & $14(20.3 \%)$ & \\
\hline Diabetes Mellitus, (n\%) & & & \\
\hline No & $297(84.9 \%)$ & $54(78.3 \%)$ & \\
\hline Yes & $53(15.1 \%)$ & $15(21.7 \%)$ & \\
\hline
\end{tabular}


Table 2

Clinicopathological characteristics of PDAC patients stratified by MUC2 expression.

\begin{tabular}{|c|c|c|c|}
\hline variables & MUC5AC negative & MUC5AC positive & $\mathbf{P}$ \\
\hline Age, $(n \%)$ & & & 0.486 \\
\hline$<62$ & $20(42.6 \%)$ & $175(47.9 \%)$ & \\
\hline$\geq 62$ & $27(57.4 \%)$ & $190(52.1 \%)$ & \\
\hline Sex, (n\%) & & & 0.145 \\
\hline Male & $32(68.1 \%)$ & $205(56.9 \%)$ & \\
\hline Female & $15(31.9 \%)$ & $155(43.1 \%)$ & \\
\hline Tumour grade, $(\mathrm{n} \%)$ & & & 0.120 \\
\hline Low & $0(0.0 \%)$ & $19(5.3 \%)$ & \\
\hline Moderate & $26(55.3 \%)$ & $220(61.3 \%)$ & \\
\hline High & $21(44.7 \%)$ & $120(33.4 \%)$ & \\
\hline Tumour stage, (n\%) & & & 0.067 \\
\hline I & $19(40.4 \%)$ & $146(40.0 \%)$ & \\
\hline II & $27(57.4 \%)$ & $170(46.6 \%)$ & \\
\hline III & $1(2.1 \%)$ & $49(13.4 \%)$ & \\
\hline T stage, $(\mathrm{n} \%)$ & & & 0.958 \\
\hline T1 & $8(17.0 \%)$ & $63(17.3 \%)$ & \\
\hline T2 & $28(59.6 \%)$ & $210(57.5 \%)$ & \\
\hline T3 & $11(23.4 \%)$ & $92(25.2 \%)$ & \\
\hline N stage, (n\%) & & & 0.084 \\
\hline NO & $21(44.7 \%)$ & $189(52.5 \%)$ & \\
\hline N1 & $24(51.1 \%)$ & $130(36.1 \%)$ & \\
\hline N2 & $2(4.3 \%)$ & $41(11.4 \%)$ & \\
\hline Tumour location, (n\%) & & & 0.058 \\
\hline Head & $20(42.6 \%)$ & $203(55.6 \%)$ & \\
\hline Body & $26(55.3 \%)$ & $156(43.3 \%)$ & \\
\hline Tail & $1(2.1 \%)$ & $1(0.3 \%)$ & \\
\hline
\end{tabular}




\begin{tabular}{|llll|}
\hline variables & MUC5AC negative & MUC5AC positive & P \\
\hline Vascular invasion, (n\%) & & & 0.345 \\
\hline No & $10(21.3 \%)$ & $100(27.8 \%)$ & \\
\hline Yes & $37(78.7 \%)$ & $260(72.2 \%)$ & \\
\hline Perineural infiltration, (n\%) & & & 0.354 \\
\hline No & $39(83.0 \%)$ & $316(87.8 \%)$ & \\
\hline Yes & $8(17.0 \%)$ & $44(12.2 \%)$ & 0.097 \\
\hline Diabetes Mellitus, (n\%) & & & \\
\hline No & $36(76.6 \%)$ & $309(85.8 \%)$ & \\
\hline Yes & $11(23.4 \%)$ & $51(14.2 \%)$ & \\
\hline
\end{tabular}


Table 3

Clinicopathological characteristics of PDAC patients stratified by MUC5 expression.

\begin{tabular}{|c|c|c|c|}
\hline variables & MUC5AC negative & MUC5AC positive & $\mathbf{P}$ \\
\hline Age, $(n \%)$ & & & 0.486 \\
\hline$<62$ & $20(42.6 \%)$ & $175(47.9 \%)$ & \\
\hline$\geq 62$ & $27(57.4 \%)$ & $190(52.1 \%)$ & \\
\hline Sex, $(n \%)$ & & & 0.145 \\
\hline Male & $32(68.1 \%)$ & $205(56.9 \%)$ & \\
\hline Female & $15(31.9 \%)$ & $155(43.1 \%)$ & \\
\hline Tumour grade, $(n \%)$ & & & 0.120 \\
\hline Low & $0(0.0 \%)$ & $19(5.3 \%)$ & \\
\hline Moderate & $26(55.3 \%)$ & $220(61.3 \%)$ & \\
\hline High & $21(44.7 \%)$ & $120(33.4 \%)$ & \\
\hline Tumour stage, (n\%) & & & 0.067 \\
\hline I & $19(40.4 \%)$ & $146(40.0 \%)$ & \\
\hline II & $27(57.4 \%)$ & $170(46.6 \%)$ & \\
\hline III & $1(2.1 \%)$ & $49(13.4 \%)$ & \\
\hline T stage, $(\mathrm{n} \%)$ & & & 0.958 \\
\hline T1 & $8(17.0 \%)$ & $63(17.3 \%)$ & \\
\hline T2 & $28(59.6 \%)$ & $210(57.5 \%)$ & \\
\hline T3 & $11(23.4 \%)$ & $92(25.2 \%)$ & \\
\hline N stage, (n\%) & & & 0.084 \\
\hline NO & $21(44.7 \%)$ & $189(52.5 \%)$ & \\
\hline N1 & $24(51.1 \%)$ & $130(36.1 \%)$ & \\
\hline N2 & $2(4.3 \%)$ & $41(11.4 \%)$ & \\
\hline Tumour location, (n\%) & & & 0.058 \\
\hline Head & $20(42.6 \%)$ & $203(55.6 \%)$ & \\
\hline Body & $26(55.3 \%)$ & $156(43.3 \%)$ & \\
\hline Tail & $1(2.1 \%)$ & $1(0.3 \%)$ & \\
\hline
\end{tabular}




\begin{tabular}{|llll|}
\hline variables & MUC5AC negative & MUC5AC positive & P \\
\hline Vascular invasion, (n\%) & & & 0.345 \\
\hline No & $10(21.3 \%)$ & $100(27.8 \%)$ & \\
\hline Yes & $37(78.7 \%)$ & $260(72.2 \%)$ & \\
\hline Perineural infiltration, (n\%) & & & 0.354 \\
\hline No & $39(83.0 \%)$ & $316(87.8 \%)$ & \\
Yes & $8(17.0 \%)$ & $44(12.2 \%)$ & \\
\hline Diabetes Mellitus, $(n \%)$ & & & 0.097 \\
\hline No & $36(76.6 \%)$ & $309(85.8 \%)$ & \\
\hline Yes & $11(23.4 \%)$ & $51(14.2 \%)$ & \\
\hline
\end{tabular}

The median age of investigated patients was 61.9 years old (30 to 84 years old). Female comprised $42.9 \%$ of the cohort and male comprised the rest. Of all the 427 investigated PDAC specimens, $92.0 \%$ (392/426) were MUC1 positive, 16.3\% (69/424) were MUC2 positive and 88.6\% (365/412) were MUC5 positive, which is coincident with the typical mucin expression pattern. Representative images of immunohistology coloration are shown in Fig. 1. Baseline and clinicopathological characteristics were summarized in Table 1, Table 2 and Table 3.

There were no statistical differences in terms of age, sex, tumour grade, tumour size, $\mathrm{N}$ stage, tumour location, vascular invasion, and diabetes mellitus history when patients were stratified into subgroups by MUC1 expression, MUC2 expression or MUC5 expression. Consequences with statistical significance were as followings: MUC1 absence was correlated with an upper proportion of TNM stage III PDAC (26.5\% versus $11.0 \%, p=0.011)$, MUC1 absence and MUC2 expression denoted perineural infiltration $(p=0.011$ and $p=0.03$, respectively).

\section{MUC1 negative expression and MUC2 positive expression indicate shorter overall survival}

At the end of the follow-up period, 31.4\% (134/427) of the investigated patients had died. The median follow-up span was 414 days (21 to 1641 days).

Patients without MUC1 expression had a shorter OS (Fig. 2a, $p=0.0079$ ). The mean survival time of MUC1 positive and negative patients was 1094 days (95\% confidence interval Cl: 1016 to 1173 days) and 571 days ( $95 \%$ Cl: 440 to 703 days) respectively. Death fraction for MUC1 positive and negative patients was $30.3 \%$ and $44.1 \%$ respectively. Patients with MUC2 expression had a shorter OS with marginal significance (Fig. $2 b, p=0.0552$ ). The mean survival time of MUC2 positive and negative patients was 792 days ( $95 \%$ Cl: 659 to 924 days) and 1108 days (95\% Cl: 1024 to 1193 days). Death fraction for MUC2 positive and negative patients was $43.5 \%$ and $28.7 \%$ respectively. MUC5 absence tended to correlate with short-term death, but was not significantly associated with long-term survival (Fig. 2c, p = 0.2714). 
MUC1 negative and MUC2 positive expression are independent risk factors for predicting PDAC patients' overall survival

The results of univariate analysis were summarized in Table 4. Risk factors with a p value less than 0.1, i.e. tumour grade, tumour stage, CA19-9 level, adjuvant chemotherapy, adjuvant radiotherapy, MUC1 expression and MUC2 expression, were integrated to make multivariate analysis. 
Table 4

Univariate and multivariate analyses of overall survival with mucins expression and clinicopathological characteristics.

\begin{tabular}{|c|c|c|c|c|c|c|c|}
\hline \multirow[t]{2}{*}{ Characteristics } & \multirow[t]{2}{*}{ Parameters } & \multicolumn{3}{|c|}{ Univariate Analysis } & \multicolumn{3}{|c|}{$\begin{array}{l}\text { Multivariate Analysis } \\
\text { (Enter Method) }\end{array}$} \\
\hline & & HR & $95 \% \mathrm{Cl}$ & $\begin{array}{l}p \\
\text { value }\end{array}$ & HR & $95 \% \mathrm{Cl}$ & $\begin{array}{l}p \\
\text { value }\end{array}$ \\
\hline \multirow[t]{2}{*}{ Age } & $\begin{array}{l}<\text { Median (63 } \\
\text { years) }\end{array}$ & 1 & & & & & \\
\hline & $\begin{array}{l}\geq \text { Median (63 } \\
\text { years) }\end{array}$ & 1.051 & $\begin{array}{l}0.747 \text { to } \\
1.478\end{array}$ & 0.776 & & & \\
\hline \multirow[t]{2}{*}{ Sex } & Male & 1 & & & & & \\
\hline & Female & 1.061 & $\begin{array}{l}0.752 \text { to } \\
1.496\end{array}$ & 0.737 & & & \\
\hline \multirow[t]{3}{*}{ Tumour Location } & $\begin{array}{l}\text { Head and Neck of } \\
\text { Pancreas }\end{array}$ & 1 & & & & & \\
\hline & Body of Pancreas & 0.970 & $\begin{array}{l}0.686 \text { to } \\
1.372\end{array}$ & 0.865 & & & \\
\hline & Tail of Pancreas & 2.212 & $\begin{array}{l}0.542 \text { to } \\
9.028\end{array}$ & 0.268 & & & \\
\hline \multirow[t]{3}{*}{ Tumour Grade } & Grade I & 1 & & & 1 & & \\
\hline & Grade II & 2.002 & $\begin{array}{l}0.630 \text { to } \\
6.366\end{array}$ & 0.240 & 1.911 & $\begin{array}{l}0.596 \text { to } \\
6.128\end{array}$ & 0.276 \\
\hline & Grade III & 3.631 & $\begin{array}{l}1.136 \text { to } \\
11.605\end{array}$ & 0.030 & 3.353 & $\begin{array}{l}1.040 \text { to } \\
10.806\end{array}$ & 0.043 \\
\hline \multirow[t]{3}{*}{ Tumour Stage } & Stage I & 1 & & & 1 & & \\
\hline & Stage II & 1.725 & $\begin{array}{l}1.176 \text { to } \\
2.532\end{array}$ & 0.005 & 1.522 & $\begin{array}{l}1.031 \text { to } \\
2.245\end{array}$ & 0.034 \\
\hline & Stage III & 1.918 & $\begin{array}{l}1.113 \text { to } \\
3.307\end{array}$ & 0.019 & 1.620 & $\begin{array}{l}0.919 \text { to } \\
2.856\end{array}$ & 0.095 \\
\hline \multirow{2}{*}{$\begin{array}{l}\text { Perineural } \\
\text { Invasion }\end{array}$} & No & 1 & & & & & \\
\hline & Yes & 0.825 & $\begin{array}{l}0.495 \text { to } \\
1.372\end{array}$ & 0.458 & & & \\
\hline \multirow{2}{*}{$\begin{array}{l}\text { Vascular Tumour } \\
\text { Thrombi }\end{array}$} & No & 1 & & & & & \\
\hline & Yes & 0.811 & $\begin{array}{l}0.556 \text { to } \\
1.182\end{array}$ & 0.276 & & & \\
\hline Diabetes Mellitus & No & 1 & & & & & \\
\hline
\end{tabular}




\begin{tabular}{|c|c|c|c|c|c|c|c|}
\hline \multirow[t]{2}{*}{ Characteristics } & \multirow[t]{2}{*}{ Parameters } & \multicolumn{3}{|c|}{ Univariate Analysis } & \multicolumn{3}{|c|}{$\begin{array}{l}\text { Multivariate Analysis } \\
\text { (Enter Method) }\end{array}$} \\
\hline & & HR & $95 \% \mathrm{Cl}$ & $\begin{array}{l}\mathrm{p} \\
\text { value }\end{array}$ & HR & $95 \% \mathrm{Cl}$ & $\begin{array}{l}\mathrm{p} \\
\text { value }\end{array}$ \\
\hline & Yes & 0.993 & $\begin{array}{l}0.610 \text { to } \\
1.614\end{array}$ & 0.976 & & & \\
\hline \multirow[t]{2}{*}{ CA19-9 Level } & $\begin{array}{l}\text { < Median (188.6 } \\
\text { U/ml) }\end{array}$ & 1 & & & 1 & & \\
\hline & $\begin{array}{l}\geq \text { Median (188.6 } \\
\mathrm{U} / \mathrm{ml} \text { ) }\end{array}$ & 1.519 & $\begin{array}{l}1.077 \text { to } \\
2.143\end{array}$ & 0.017 & 1.391 & $\begin{array}{l}0.978 \text { to } \\
1.980\end{array}$ & 0.067 \\
\hline \multirow{2}{*}{$\begin{array}{l}\text { Adjuvant } \\
\text { Chemotherapy }\end{array}$} & Yes & 1 & & & 1 & & \\
\hline & No & 2.032 & $\begin{array}{l}1.367 \text { to } \\
3.022\end{array}$ & $\hat{0} .001$ & 2.055 & $\begin{array}{l}1.369 \text { to } \\
3.085\end{array}$ & 0.001 \\
\hline \multirow{2}{*}{$\begin{array}{l}\text { Adjuvant } \\
\text { Radiotherapy }\end{array}$} & Yes & 1 & & & 1 & & \\
\hline & No & 1.937 & $\begin{array}{l}0.983 \text { to } \\
3.816\end{array}$ & 0.056 & 1.621 & $\begin{array}{l}0.810 \text { to } \\
3.244\end{array}$ & 0.173 \\
\hline \multirow[t]{2}{*}{ MUC1 } & negative & 1 & & & & & \\
\hline & positive & 0.488 & $\begin{array}{l}0.284 \text { to } \\
0.839\end{array}$ & 0.009 & 0.492 & $\begin{array}{l}0.274 \text { to } \\
0.883\end{array}$ & 0.017 \\
\hline \multirow[t]{2}{*}{ MUC2 } & negative & 1 & & & & & \\
\hline & positive & 1.479 & $\begin{array}{l}0.988 \text { to } \\
2.214\end{array}$ & 0.057 & 1.596 & $\begin{array}{l}1.061 \text { to } \\
2.401\end{array}$ & 0.025 \\
\hline \multirow[t]{2}{*}{ MUC5 } & negative & 1 & & & & & \\
\hline & positive & 0.761 & $\begin{array}{l}0.466 \text { to } \\
1.241\end{array}$ & 0.273 & & & \\
\hline
\end{tabular}

Multivariable-adjusted Cox regression model showed that the HR for mortality comparing patients with to those without MUC1 expression was 0.492 ( $95 \%$ Cl: 0.274 to $0.883, p=0.017$ ), mortality comparing patients with to those without MUC2 expression was 1.596 (95\% Cl: 1.061 to $2.401, p=0.025$ ). Therefore, MUC1 negative and MUC2 positive expression were considered as independent risk factors for prognosticating survival time of PDAC patients after surgical section.

High tumour grade, high tumour stage and not receiving adjuvant chemotherapy were also independently correlated with increased mortality.

\section{Discussion}


PDAC is a malignancy characterized by high mortality and unsatisfactory survival. Its strikingly low 5year survival and high recurrence and metastasis rate necessitate the need to find reliable prognostic markers, not only to predict patients' survival but also help find potential therapy targets.

One remarkable hallmark of PDAC is abundant dense stroma ${ }^{20}$, which enriches multiple of aberrantly expressed mucins and merit further investigation. Emerging roles of mucins are discovered in the progression, development and metastasis of malignancies, including intestinal cancer, ovarian cancer and haematological malignancies ${ }^{21}$. Overexpressed membrane-bound mucins interact with receptor tyrosine kinases such as epidermal growth factor receptor (EGFR) and attenuate signalling pathways downstream of transforming growth factor-a (TGF-a) and EGFR ${ }^{22}$; hence, play protective roles for cancer cells. Therefore, membrane-bound MUC1 is generally recognized as an oncoprotein in epithelial cancers $^{11,23}$. However, the function of MUC1 can be switched depending on its glycosylation status, based on which MUC1 has a dual function of pro-inflammatory and anti-inflammatory factors ${ }^{24}$. In addition, MUC1 absence is associated with altered tumour microenvironment (TME). MUC1 deficient PDAC exhibits significant different immune reaction compared to wildtype PDAC in mice models ${ }^{25}$, MUC1 absence results in the proliferation and activation of myeloid-derived suppressor cells (MDSC) and regulatory $T$ cells (Treg), which correspond to immunosuppressive tumor microenvironment and is responsible for tumor immune evasion ${ }^{26}$. Besides, transmembrane mucins contribute to the junction and the polarity of epithelial cell, loss of which promotes malignant epithelial-mesenchymal transition (EMT) and tumorigenesis, and downregulation of membrane-bound mucins doubtlessly reduces the immunogenicity of tumor cells.

Secreted mucins, such as MUC2, form protective mucus barrier and help epithelial cells get rid of inflammation and tumorigenesis in physiological condition. Paradoxically, MUC2 has increased expression level in certain types of gastrointestinal malignancies ${ }^{21,27}$, which denotes that MUC2 may also be employed by cancer cells and function as mucous barrier against anti-tumour immune reaction. MUC5 is another secreted mucin and promotes KLF4 mediated PDAC cancerous stemness ${ }^{9}$. In addition, CA19-9, the most commonly used prognostic marker for pancreatic cancerous disease, is present on the surface of MUC1 and MUC5 20,28; With respect to the recent discovery that CA19-9 bolsters PDAC initiation and progression ${ }^{29}$, the interaction between mucins and CA19-9 suggests that mucins are not merely prognostic factors but also participate in the onset and advancement of PDAC.

Mice models and human studies reflect that mucin expression pattern is changed throughout the progression of PDAC ${ }^{15}$. MUC1 and MUC5 become the predominantly overexpressed mucins in pancreatic malignancies ${ }^{3}$, and MUC2 is commonly believed to be absent in normal pancreatic tissue and PDAC ${ }^{30}$. Nonetheless, there remains a subgroup of PDAC patients whose tumour specimens are either MUC1 negative, MUC2 positive or MUC5 negative, and this atypical subgroup accounts for $31.2 \%$ of the total PDAC patients according to our cohort; hence, there raises the issue to investigate these PDAC patients with atypical mucin expression for the purpose of fathoming out the association between mucin expression and prognosis of PDAC patients. 
However, prior researchers had contradictory conclusions about the correlation between mucin expression and PDAC patients' prognosis ${ }^{31}$. Mikiko Takikita et al investigated 120 well differentiated PDAC patients and found MUC2 expression predicts shorter survival (hazard ratio, $H R=1.6)^{27}$, whereas $\square$ Francesco Pantano et al researched 59 radically resected PDAC patients and drew the opposite conclusion that MUC2 positive patients have longer survival, and MUC5 do not have prognostic value ${ }^{32}$. खMichiyo Higashi et al examined 114 PDAC and proposed that MUC5 expression was associated with longer survival ( $\mathrm{HR}=$ $0.6)$ whereas MUC1 and MUC2 did not show prognostic value ${ }^{16}$. WJordan M. Winter analysed 137 PDAC patients and found that MUC1 overexpression was predictive of early cancer-specific death, and MUC2 overexpression was associated with longer survival ${ }^{33}$. खYuji Hinoda surveyed 70 advanced PDAC patients and suggested that MUC1 expression indicates PDAC progression and shorter survival ${ }^{34}$. Seiya Yokoyama claimed that a patient subgroup with multinomial overexpression of MUC1, MUC2 and MUC4 had worse survival compared to the control

cluster $^{8}$. \Arne Westgaard investigated 67 patients and showed that MUC1 or MUC4 expression is a risk factor for prognosis $(H R=2.02)^{35}$.

Recent researches about MUC1 and PDAC patients' survival are summarized in Table 5. The erratic conclusions of these foregoing researches can be attributed to insufficient investigated PDAC patients and unexpected MUC1 positive rate, so their cohorts are not representative. Therefore, it is vital to use a larger cohort to elucidate the correlation between mucin expression and clinical outcomes of PDAC patients.

In this study, we used a relatively large cohort and discovered that MUC1 negative expression and MUC2 positive expression were associated with worse OS in PDAC patients. After controlling for age, gender, tumour location, tumour grade, tumour stage, perineural invasion, vascular thrombi, diabetes mellitus history, baseline CA19-9 serum level, adjuvant chemotherapy and adjuvant radiotherapy treatment history, MUC1 negative expression and MUC2 positive expression were identified as independent risk factors. Although MUC5 did not show prognostic value, we noticed that MUC5 negative group had more death event compared to MUC5 positive group in the early stage of following-up.

Our results resolve the aforementioned controversy, and conclusion of our study indicates that MUC1 absence is a risk factor for PDAC in Chinese population. Further study is demanded to clarify the effect of MUC1 glycosylation status on PDAC. Our study also proposed that MUC2 positive expression predicts worse survival in PDAC, which can be a clinical evidence of cancer cells exploiting MUC2 to form protective mucous barrier to evade from immune attack. In conclusion, atypical mucin expression pattern, i.e. MUC1 absence or MUC2 expression, prognosticates shorter OS time in PDAC patients. 
Table 5

Prior studies about MUC1 expression and prognosis of PDAC patients.

\begin{tabular}{|c|c|c|c|c|c|}
\hline Researcher & $\begin{array}{l}\text { Number of } \\
\text { investigated } \\
\text { PDAC } \\
\text { patients }\end{array}$ & $\begin{array}{l}\text { MUC1 } \\
\text { positive } \\
\text { rate }\end{array}$ & Conclusion & $\begin{array}{l}\text { Journal and } \\
\text { year }\end{array}$ & PMID \\
\hline \multirow[t]{2}{*}{$\begin{array}{l}\text { Mikiko } \\
\text { Takikita et } \\
\text { al }\end{array}$} & 154 & $90.3 \%$ & $\begin{array}{l}\text { 1, MUC1 expression is } \\
\text { associated with longer } \\
\text { survival in PDAC. }\end{array}$ & $\begin{array}{l}\text { Cancer } \\
\text { Research, } 2009\end{array}$ & • 19276352 \\
\hline & & & $\begin{array}{l}\text { 2, MUC1 expression is } \\
\text { associated with shorter } \\
\text { median survival in well- } \\
\text { and moderately } \\
\text { differentiated PDAC. }\end{array}$ & & \\
\hline \multirow[t]{2}{*}{$\begin{array}{l}\text { पJordan M. } \\
\text { Winter et } \\
\text { al }\end{array}$} & 137 & $85.4 \%$ & $\begin{array}{l}1, \text { MUC1 or MSLN }{ }^{\star} \\
\text { expression is associated } \\
\text { with shorter survival. }\end{array}$ & $\begin{array}{l}\text { PLOS ONE, } \\
2012\end{array}$ & ' 22792233 \\
\hline & & & $\begin{array}{l}\text { 2. MUC2 expression is } \\
\text { associated with longer } \\
\text { survival }\end{array}$ & & \\
\hline \multirow[t]{2}{*}{$\begin{array}{l}\text { Michiyo } \\
\text { Higashi et } \\
\text { al }\end{array}$} & 114 & $87.7 \%$ & $\begin{array}{l}\text { 1, MUC1, MUC2 MUC4 } \\
\text { show no relationship with } \\
\text { any clinicopathologic } \\
\text { features. }\end{array}$ & Pancreas, 2015 & ' 25906442 \\
\hline & & & $\begin{array}{l}\text { 2, MUC5, MUC6, MUC16 } \\
\text { are prognostic factors for } \\
\text { PDAC patients. }\end{array}$ & & \\
\hline $\begin{array}{l}\text { GYuji } \\
\text { Hinoda et } \\
\text { al }\end{array}$ & 70 & $55.8 \%$ & $\begin{array}{l}\text { MUC1 expression is } \\
\text { associated with worse OS* } \\
\text { in stage IV PDAC, but not } \\
\text { in stage III PDAC }\end{array}$ & $\begin{array}{l}\text { Journal of } \\
\text { Gastroenterol, } \\
2003\end{array}$ & • 14714254 \\
\hline $\begin{array}{l}\text { Arne } \\
\text { Westgaard } \\
\text { et al }\end{array}$ & 114 & $36.9 \%$ & $\begin{array}{l}\text { MUC1 or MUC4 expression } \\
\text { predicts a poorer } \\
\text { prognosis }\end{array}$ & $\begin{array}{l}\text { Histopathology, } \\
2009\end{array}$ & • 19236510 \\
\hline
\end{tabular}

PDAC: pancreatic ductal adenocarcinoma; MSLN: mesothelin; OS: overall survival; Cluster 1: patients with multinomial overexpression of MUC1, MUC2 and MUC4

Our research has the strength of solely focusing on resected and pathologically diagnosed PDAC, which makes our study more homogenous. In addition, our research has a relatively large cohort consisted of 427 PDAC patients, which makes our results more representative and convincing. The retrospective design becomes the major limitation of our study. Besides, since our research is a surgical cohort, patients with unresectable PDAC were excluded. We hope our clinical findings contribute to future exploration of targeted therapy in PDAC. 


\begin{tabular}{|c|c|c|c|c|c|}
\hline Researcher & $\begin{array}{l}\text { Number of } \\
\text { investigated } \\
\text { PDAC }^{*} \\
\text { patients }\end{array}$ & $\begin{array}{l}\text { MUC1 } \\
\text { positive } \\
\text { rate }\end{array}$ & Conclusion & $\begin{array}{l}\text { Journal and } \\
\text { year }\end{array}$ & PMID \\
\hline $\begin{array}{l}\text { Seiya } \\
\text { Yokoyama } \\
\text { et al }\end{array}$ & 271 & $\begin{array}{l}31.7 \% \\
\text { patients } \\
\text { in } \\
\text { cluster } \\
1^{*}\end{array}$ & $\begin{array}{l}\text { Patients of cluster } 1 \text { had } \\
\text { worse survival compared } \\
\text { to the others }\end{array}$ & $\begin{array}{l}\text { Clinical cancer } \\
\text { research, } 2020\end{array}$ & 31992588 \\
\hline \multicolumn{6}{|c|}{$\begin{array}{l}\text { PDAC: pancreatic ductal adenocarcinoma; MSLN: mesothelin; OS: overall survival; Cluster 1: patients } \\
\text { with multinomial overexpression of MUC1, MUC2 and MUC4 }\end{array}$} \\
\hline \multicolumn{6}{|c|}{$\begin{array}{l}\text { Our research has the strength of solely focusing on resected and pathologically diagnosed PDAC, } \\
\text { which makes our study more homogenous. In addition, our research has a relatively large cohort } \\
\text { consisted of } 427 \text { PDAC patients, which makes our results more representative and convincing. The } \\
\text { retrospective design becomes the major limitation of our study. Besides, since our research is a } \\
\text { surgical cohort, patients with unresectable PDAC were excluded. We hope our clinical findings } \\
\text { contribute to future exploration of targeted therapy in PDAC. }\end{array}$} \\
\hline
\end{tabular}

\section{Abbreviations}

AJCC: the American Joint Committee on Cancer

CA153: Carbohydrate Antigen 153

CA19-9: Carbohydrate Antigen 19-9

Cl: Confidence Interval

EGFR: Epidermal Growth Factor Receptor

EMT: Epithelial-Mesenchymal Transition

HR: Hazard Ratio

IHC: Immunohistochemistry

IPMN: Intraductal Papillary Mucinous Neoplasm

Mab: Monoclonal Antibody

MCN: Mucinous Cystic Neoplasm

MDSC: Myeloid-Derived Suppressor Cells

OS: Overall Survival

PDAC: Pancreatic Ductal Adenocarcinoma 
TGF-a: Transforming Growth Factor-a

TME: Tumour microenvironment

Treg: Regulatory T Cells

\section{Declarations}

\section{Ethics approval and consent to participate}

This study was approved by the Ethics Board of Shanghai Cancer Center, Fudan University, and all patients involved in this study provided informed consent for the use of their personal data for research purposes. Informed consent was obtained from all individual participants included in the study.

\section{Consent for publication}

Written informed consent for publication was obtained from all participants.

\section{Availability of data and materials}

The datasets used and analysed during this study available from the corresponding author on reasonable request.

\section{Conflict of interest}

The authors declare that they have no competing interests in this section.

\section{Funding}

This work was supported by the National Natural Science Foundation of China (grant numbers 82072693, 81902417, 82172884, U21A20374), the Scientific Innovation Project of Shanghai Education Committee (2019-01-07-00-07-E00057), Shanghai Municipal Science and Technology Major Project (21JC1401500), Clinical and Scientific Innovation Project of Shanghai Hospital Development Center (SHDC12018109), Clinical Research Plan of Shanghai Hospital Development Center (SHDC2020CR1006A), National Key Research and Development Program of China (2020YFA0803202), and Xuhui District Artificial Intelligence Medical Hospital Cooperation Project (2021-011).

\section{Authors' contributions}

Conceptualization and Funding acquisition: Xianjun Yu and Chen Liu. Project Administration and Supervision: He Cheng. Validation: He Cheng and Yusheng Chen. Data Collection: Yu Liu, Ruijie Wang, Zhengjie Dai, and Yesiboli Tasiheng. Immunohistochemical evaluation: Xuan Lin and Xuan Zou. Writing original draft: Yunzhen Qian and Yitao Gong. Writing - review editing: Xu Wang and Guopei Luo.

\section{Acknowledgements}


Not applicable.

\section{References}

1. Rahib L, Smith BD, Aizenberg R, Rosenzweig AB, Fleshman JM, Matrisian LM. Projecting cancer incidence and deaths to 2030: The unexpected burden of thyroid, liver, and pancreas cancers in the united states. Cancer Res. 2014;74(11):2913-2921. doi:10.1158/0008-5472.CAN-14-0155

2. Jonckheere N, Skrypek N, van Seuningen I. Mucins and pancreatic cancer. Cancers (Basel). 2010;2(4):1794-1812. doi:10.3390/cancers2041794

3. Carrara S, Cangi MG, Arcidiacono PG, et al. Mucin expression pattern in pancreatic diseases: Findings from EUS-guided fine-needle aspiration biopsies. Am J Gastroenterol. 2011;106(7):13591363. doi:10.1038/ajg.2011.22

4. Gum ET, Dahiya R, Kim YS, Yan PS, Cherwitz DL. Heterogeneity of Mucin Gene Expression in Normal and Neoplastic Tissues. Cancer Res. 1993;53(3):641-651.

5. Adsay NV. Role of MUC genes and mucins in pancreatic neoplasia. Am J Gastroenterol. 2006;101(10):2330-2332. doi:10.1111/j.1572-0241.2006.00934.x

6. Haab BB, Porter A, Yue T, et al. Glycosylation variants of mucins and CEACAMs as candidate biomarkers for the diagnosis of pancreatic cystic neoplasms. Ann Surg. 2010;251(5):937-945. doi:10.1097/SLA.0b013e3181d7738d

7. Ringel J, Löhr M. The MUC gene family: Their role in diagnosis and early detection of pancreatic cancer. Mol Cancer. 2003;2:7-11. doi:10.1186/1476-4598-2-9

8. Yokoyama S, Hamada T, Higashi M, et al. Predicted Prognosis of Patients with Pancreatic Cancer by Machine Learning. Clin Cancer Res. 2020;26(10):2411-2421. doi:10.1158/1078-0432.CCR-19-1247

9. Ganguly K, Krishn SR, Rachagani S, et al. Secretory Mucin 5AC Promotes Neoplastic Progression by Augmenting KLF4-Mediated Pancreatic Cancer Cell Stemness. Cancer Res. 2021;81(1):91-102. doi:10.1158/0008-5472.CAN-20-1293

10. Gunda V, Souchek J, Abrego J, et al. MUC1-mediated metabolic alterations regulate response to radiotherapy in pancreatic cancer. Clin Cancer Res. 2017;23(19):5881-5891. doi:10.1158/10780432.CCR-17-1151

11. Chen W, Zhang Z, Zhang S, Zhu P, Ko JKS, Yung KKL. Muc1: Structure, function, and clinic application in epithelial cancers. Int J Mol Sci. 2021;22(12):1-15. doi:10.3390/ijms22126567

12. Gao T, Cen Q, Lei H. A review on development of MUC1-based cancer vaccine. Biomed Pharmacother. 2020;132(August):110888. doi:10.1016/j.biopha.2020.110888

13. Tsang KY, Palena C, Gulley J, Arlen P, Schlom J. A Human Cytotoxic T-Lymphocyte Epitope and Its Agonist Epitope from the Nonvariable Number of Tandem Repeat Sequence of MUC-1. Clin Cancer Res. 2004;10(6):2139-2149. doi:10.1158/1078-0432.CCR-1011-03

14. Posey AD, Schwab RD, Boesteanu AC, et al. Engineered CAR T Cells Targeting the Cancer-Associated Tn-Glycoform of the Membrane Mucin MUC1 Control Adenocarcinoma. Immunity. 2016;44(6):1444- 
1454. doi:10.1016/j.immuni.2016.05.014

15. Rachagani S, Torres MP, Kumar S, et al. Mucin (Muc) expression during pancreatic cancer progression in spontaneous mouse model: Potential implications for diagnosis and therapy. $J$ Hematol Oncol. 2012;5:1-12. doi:10.1186/1756-8722-5-68

16. Higashi M, Yokoyama S, Yamamoto T, et al. Mucin Expression in Endoscopic Ultrasound-Guided Fine-Needle Aspiration Specimens Is a Useful Prognostic Factor in Pancreatic Ductal Adenocarcinoma. Pancreas. 2015;44(5):728-734. doi:10.1097/MPA.0000000000000362

17. Sierzega M, Młynarski D, Tomaszewska R, Kulig J. Semiquantitative immunohistochemistry for mucin (MUC1, MUC2, MUC3, MUC4, MUC5AC, and MUC6) profiling of pancreatic ductal cell adenocarcinoma improves diagnostic and prognostic performance. Histopathology. 2016;69(4):582591. doi:10.1111/his.12994

18. Nagtegaal ID, Odze RD, Klimstra D, et al. The 2019 WHO classification of tumours of the digestive system. Histopathology. 2020;76(2):182-188. doi:10.1111/his.13975

19. Chun YS, Pawlik TM, Vauthey J-N. 8th Edition of the AJCC Cancer Staging Manual: Pancreas and Hepatobiliary Cancers. Ann Surg Oncol. 2018;25(4):845-847. doi:10.1245/s10434-017-6025-x

20. Kaur S, Kumar S, Momi N, Sasson AR, Batra SK. Mucins in pancreatic cancer and its microenvironment. Nat Rev Gastroenterol Hepatol. 2013;10(10):607-620. doi:10.1038/nrgastro.2013.120

21. Donald W. Kufe. Mucins in cancer: function, prognosis and therapy. Nat Rev Cancer. 2009;9(12):874885. doi:10.1038/nrc2761.Mucins

22. Pochampalli MR, Bitler BG, Schroeder JA. Transforming growth factor a-dependent cancer progression is modulated by Muc1. Cancer Res. 2007;67(14):6591-6598. doi:10.1158/00085472.CAN-06-4518

23. Nath S, Mukherjee P. MUC1: A multifaceted oncoprotein with a key role in cancer progression. Trends Mol Med. 2014;20(6):332-342. doi:10.1016/j.molmed.2014.02.007

24. Bose M, Mukherjee P. Microbe-MUC1 Crosstalk in Cancer-Associated Infections. Trends Mol Med. 2020;26(3):324-336. doi:10.1016/j.molmed.2019.10.003

25. Mahnaz S, Roy LD, Bose M, De C, Nath S, Mukherjee P. Repression of MUC1 promotes expansion and suppressive function of myeloid-derived suppressor cells in pancreatic ductal adenocarcinoma and breast cancer murine models. bioRxiv. 2020:1-15. doi:10.1101/2020.12.07.415299

26. Safarzadeh E, Orangi M, Mohammadi H, Babaie F, Baradaran B. Myeloid-derived suppressor cells: Important contributors to tumor progression and metastasis. J Cell Physiol. 2018;233(4):3024-3036. doi:10.1002/jcp.26075

27. Takikita M, Altekruse S, Lynch CF, et al. Associations between selected biomarkers and prognosis in population-based pancreatic cancer tissue microarray. Cancer Res. 2009;69(7):2950-2955. doi:10.1158/0008-5472.CAN-08-3879

28. Akagi J, Takai E, Tamori Y, Nakagawa K, Ogawa M. CA19-9 epitope a possible marker for MUC-1/Y protein. Int J Oncol. 2001;18(5):1085-1091. doi:10.3892/ijo.18.5.1085 
29. Engle DD, Tiriac $H$, Rivera KD, et al. The glycan CA19-9 promotes pancreatitis and pancreatic cancer in mice. Science (80-). 2019;364(6446):1156-1162. doi:10.1126/science.aaw3145

30. Chhieng DC, Benson E, Eltoum I, et al. MUC1 and MUC2 Expression in Pancreatic Ductal Carcinoma Obtained by Fine-Needle Aspiration. Cancer. 2003;99(6):365-371. doi:10.1002/cncr.11857

31. Manne A, Esnakula A, Abushahin L, Tsung A. Understanding the clinical impact of muc5ac expression on pancreatic ductal adenocarcinoma. Cancers (Basel). 2021;13(12):1-13. doi:10.3390/cancers13123059

32. Pantano F, Baldi A, Santini D, et al. MUC2 but not MUC5 expression correlates with prognosis in radically resected pancreatic cancer patients. Cancer Biol Ther. 2009;8(11):996-999. doi:10.4161/cbt.8.11.8537

33. Winter JM, Tang LH, Klimstra DS, et al. A novel survival-based tissue microarray of pancreatic cancer validates muc1 and mesothelin as biomarkers. PLoS One. 2012;7(7):1-10. doi:10.1371/journal.pone.0040157

34. Hinoda $Y$, Ikematsu $Y$, Horinochi $M$, et al. Increased expression of MUC1 in advanced pancreatic cancer. J Gastroenterol. 2003;38(12):1162-1166. doi:10.1007/s00535-003-1224-6

35. Westgaard A, Schjølberg AR, Cvancarova M, Eide TJ, Clausen OPF, Gladhaug IP. Differentiation markers in pancreatic head adenocarcinomas: MUC1 and MUC4 expression indicates poor prognosis in pancreatobiliary differentiated tumours. Histopathology. 2009;54(3):337-347. doi:10.1111/j.13652559.2009.03227.x

\section{Figures}



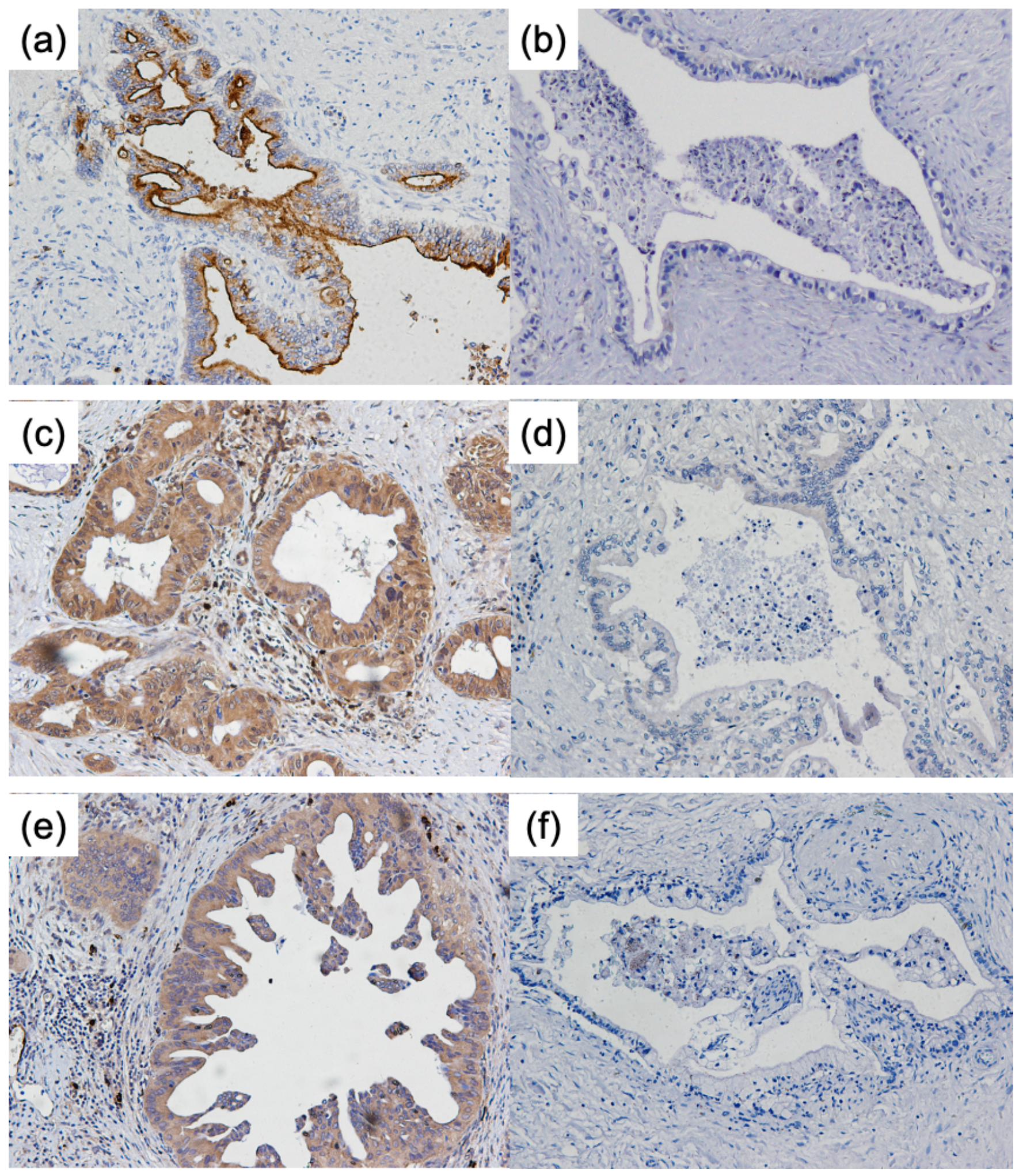

\section{Figure 1}

Representative immunohistochemical coloration of mucin expression in PDAC tissues.

$(a, b)$ Representative images of MUC1 positive and negative expression in PDAC tissues, MUC1 positive expression are only considered when positive coloration located in the apical membrane of PDAC cells; (c, d) Representative images of MUC2 positive and negative expression in PDAC tissues, MUC2 positive 
expression are only considered when positive coloration located in the cytoplasm of PDAC cells. $(e, f)$ Representative images of MUC5 positive and negative expression in PDAC tissues, MUC5 positive expression are only considered when positive coloration located in the cytoplasm of PDAC cells.

Abbreviations: PDAC, pancreatic ductal adenocarcinoma

(a)

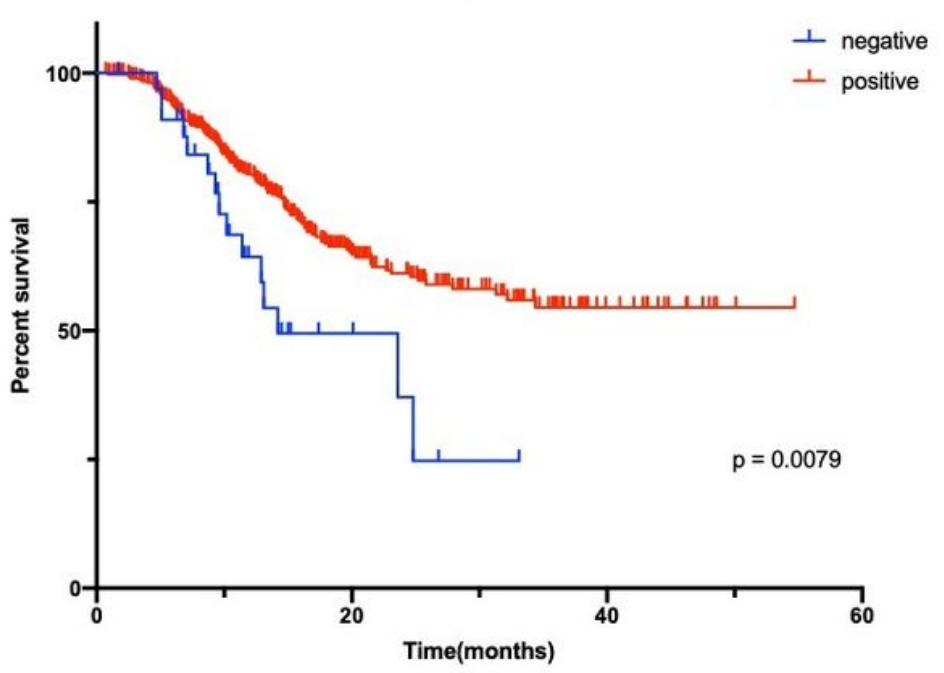

(c)
MUC1

MUC5AC (b)

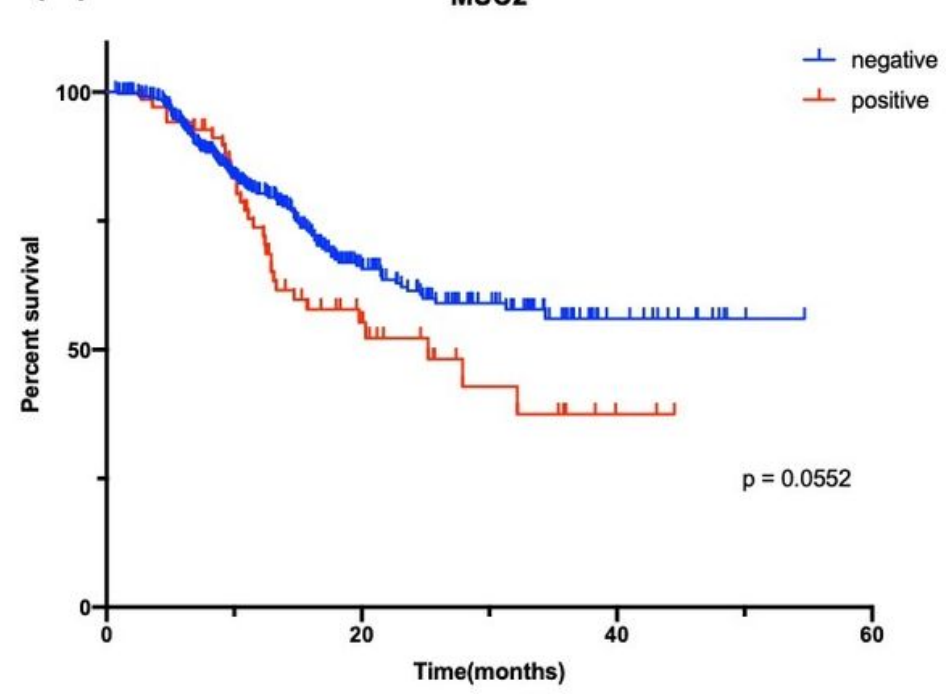

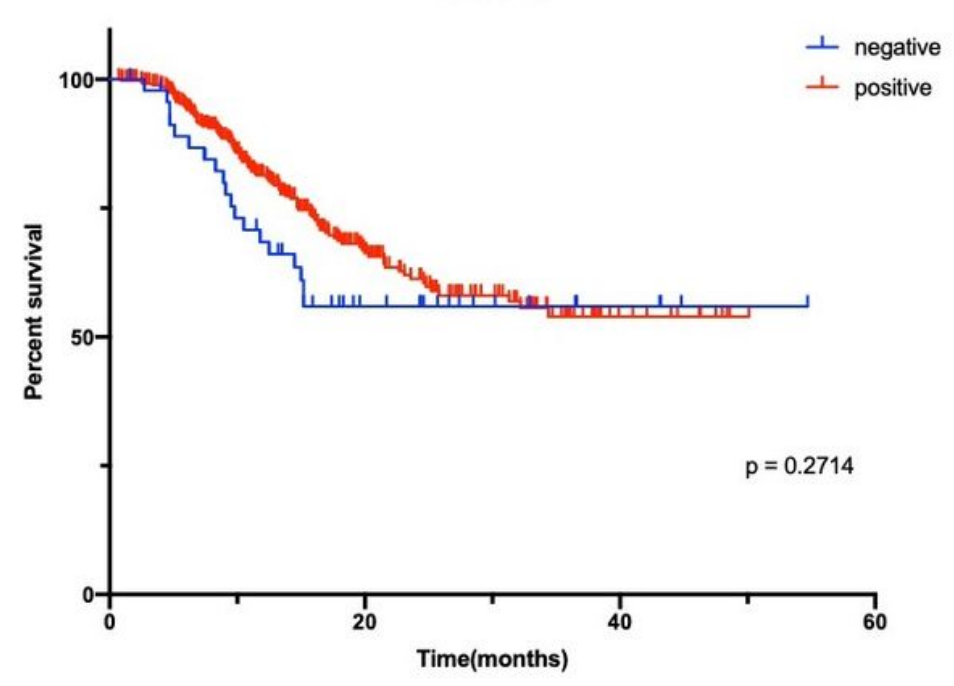

Figure 2

Survival curves of PDAC patients in relation to mucin expression according to Kaplan-Meier's method.

(a) MUC1 negative patients $(n=34)$ had worse survival compared to MUC1 positive patients $(n=392)$.

(b) MUC2 positive patients $(n=69)$ tended to survive a shorter time compared to MUC2 negative patients $(\mathrm{n}=355)$. (c) there was no statistical significance of overall survival between the subgroups stratified by MUC5 expression ( $n=365$ and $n=47$ respectively). 
Page 27/27 